\title{
A dialética conhecimento/transformação do mundo no legado marxista
}

\author{
The dialectic knowledge/transformation of the world, in the Marxist legacy

\section{Benedito de Jesus Pinheiro FERREIRA*} \\ Joana Valente SANTANA**
}

\begin{abstract}
Resumo: Este ensaio apresenta uma discussão acerca da centralidade do método dialético marxiano e da necessidade da sua correta apropriação como elemento de interpretação e transformação da realidade. Com base em estudo bibliográfico, discute a questão da superação do capitalismo diante dos profundos impasses com os quais a humanidade se defronta no atual período de intensas contradições do capital. A partir do legado da tradição marxista, reflete acerca das possibilidades de enriquecimento da luta da esquerda para a construção de um projeto anticapitalista, condição para a efetiva emancipação humana. Finalmente, conclui que tal projeto deve orientar-se pela centralidade da luta de classes e pela perspectiva da totalidade, superando, portanto, a fragmentação no campo das lutas sociais.

Palavras-chave: Método dialético. Produção de conhecimento. Esquerda revolucionária. Emancipação humana.
\end{abstract}

Abstract: This essay presents a discussion around the centrality of the Marxist dialectic method and the need for its proper appropriation as an element of interpretation and transformation of reality. Based on a bibliographical study, it discusses the question of overcoming capitalism in the face of the profound impasses that humanity faces in the current period of intense contradictions of capital. From the legacy of the Marxist tradition, it reflects on the possibilities for enriching the Left's struggle in constructing an anti-capitalist project, a condition for effective human emancipation. It concludes that such a project must be guided by the centrality of the class struggle and from the perspective of totality, thus overcoming the fragmentation in the field of social struggles.

Keywords: Dialectical method. Knowledge production. Revolutionary left. Human emancipation.

Submetido em: 15/4/2018. Revisado em: 18/7/2018. Aceito em: 3/8/2018.

\section{INTRODUÇÃO}

A atividade prática é, por isso, simultaneamente subjetiva e objetiva, dependente e independente de sua consciência, ideal e material, e tudo isso em unidade indissolúvel.

Adolfo Sanchez Vásquez

\footnotetext{
* Professor. Doutor em Engenharia de Sistemas e Computação pela Universidade Federal do Rio de Janeiro. Professor Titular do Programa de Pós-graduação em Educação e da Faculdade de Computação da Universidade Federal do Pará. Rua Augusto Corrêa, 1, Guamá, Belém (PA), CEP.: 66073-040. E-mail: <ferreira@ufpa.br>. ORC ID: <http://orcid.org/oooo-ooo3-1949-5077>.

** Assistente Social. Doutora em Serviço Social pela Universidade Federal do Rio de Janeiro. Professora Associada II do Programa de Pós-graduação em Serviço Social e da Faculdade de Serviço Social da Universidade Federal do Pará. Rua Augusto Corrêa, 1, Belém (PA), CEP.: 66073-040. Bolsa Produtividade em Pesquisa (PQ2)/CNPq. E-mail: <joanavalente@ufpa.br>. ORC ID: <http://orcid.org/oooo-ooo3-4033$1317>$.
} 


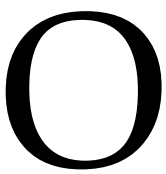

presente ensaio, de natureza bibliográfica, tem por objetivo discutir a relação dialética entre conhecimento e transformação da realidade presente no legado de Karl Marx e Friedrich Engels ${ }^{1}$, dando centralidade ao método dialético de produção de conhecimento, como elemento primordial para a construção do projeto de transformação revolucionária da sociedade, tarefa urgente da esquerda diante da realidade contemporânea.

Após décadas de predomínio de políticas neoliberais, assiste-se, no tempo presente, ao desenvolvimento de crescentes contradições no capitalismo: crise crônica do capital ${ }^{2}$, desemprego em níveis elevados, degradação de direitos sociais, aumento da concentração de renda, violações de direitos humanos (migrações, deslocamento por guerra, assassinatos nas periferias urbanas) e destruição da natureza, dentre outras. Harvey (2016) faz um questionamento sobre as possibilidades presentes de interpretação radical da realidade, apontando como fundamental o estudo das contradições do capital. Para o autor,

\begin{abstract}
Não são apenas as elites capitalistas e seus seguidores intelectuais e acadêmicos que parecem incapazes de romper radicalmente com o passado ou definir uma saída viável para a lamuriosa crise [...]. As forças da esquerda tradicional (partidos políticos e sindicatos) são nitidamente incapazes de configurar uma oposição sólida ao poder do capital. Há trinta anos elas são derrotadas pelos ataques ideológicos e políticos da direita, enquanto o socialismo democrático é desacreditado [...] Essa esquerda [...] que estranhamente faz eco a uma ética libertária e até neoliberal do antiestatismo, é fomentada intelectualmente por pensadores como Michel Foucault e todos aqueles que reuniram os fragmentos pós-modernos sob a bandeira de um pós-estruturalismo amplamente incompreensível que favorece a política identitária e evita a análise de classes (HARVEY, 2016, p. 11-12).
\end{abstract}

Nessa perspectiva, questiona-se quais os desafios e quais os sujeitos, no tempo presente, capazes de interpretar as contradições da ordem burguesa tendo, no horizonte, a superação dessa ordem como condição da emancipação humana.

A elaboração teórica de Karl Marx acerca da dialética entre conhecimento e transformação da realidade é um meio indispensável para a consolidação de uma prática revolucionária. Marx, ao incorporar e superar os fundamentos progressistas do programa sociocultural da modernidade, buscou as raízes da desigualdade no modo de produção capitalista ${ }^{3}$. Assim, a práxis revolucionária humana é notavelmente enriquecida com a síntese elaborada a partir das mais altas produções culturais até então realizadas pela humanidade. A famosa tese XI ad Feuerbach sintetiza a nova concepção de mundo, exigindo, para além do esforço de

\footnotetext{
${ }^{1}$ Doravante, neste texto, subentenda-se, na referência a Marx ou ao adjetivo marxiano, a fundamental colaboração de Friedrich Engels.

${ }^{2}$ Segundo Harvey (2016, p. 12), “[...] o motor econômico do capitalismo está nitidamente passando por dificuldades".

3 A burguesia, que fora revolucionária quanto ao avanço das forças produtivas em relação ao modo de produção feudal, torna-se conservadora à medida que as contradições de classe ganham centralidade na cena política (COUTINHO, 2010). A manutenção da propriedade privada e da alienação do trabalho deixou intocável a essência da desigualdade. Além disso, a desigualdade econômica e social existente em sociedades pré-capitalistas assume, pelo alto desenvolvimento das forças produtivas, uma forte proporção na ordem burguesa: contraditoriamente, produz-se muito mais riqueza e igualmente pobreza, mediante um sistema de apropriação privada das mercadorias produzidas.
}

Argum., Vitória, v. 10, n. 2, p. 70-83, maio/ago. 2018. 
interpretação da realidade, a premência da sua transformação radical, irrealizável, entretanto, como mostra a trajetória de vida de Marx e Engels, sem sua contraparte: o reiterado, e igualmente radical, esforço de conhecimento dessa realidade.

Assim, este estudo analisa a relação inseparável entre os polos compreensão/transformação, em termos onto-gnosiológicos, valorizando o estudo, em bases dialéticas, das mediações teórico/práticas como condição para a compreensão das possibilidades de transformação revolucionária da atual sociedade, urgentemente demandada face ao grau de efetivação da barbárie.

Estrutura-se o texto da seguinte forma: a seção 1 discute a tradição marxista e o necessário enfrentamento dos reducionismos teóricos e políticos; a seção 2 discute o método marxiano como guia na interpretação/transformação da realidade; a seção 3 discute a importância da produção de mediações teórico/práticas na elaboração de um projeto revolucionário. Nas considerações finais, são apresentadas reflexões acerca das possibilidades de enriquecimento da prática revolucionária da esquerda a partir do legado marxiano.

\section{A TRADIÇÃO MARXISTA E O NECESSÁRIO ENFRENTAMENTO DOS REDUCIONISMOS}

O marxismo originou-se do "[...] máximo desenvolvimento da cultura da primeira metade do século XIX [...]” (GRAMSCI, 1995, p. 110), como síntese orientada no princípio dialético de superação por incorporação, na atitude em relação ao conhecimento estabelecida pela máxima "colocar-se ao ombro dos gigantes" para melhor enxergar. Em sua forma teórica, inicialmente se constitui como "[...] uma continuação aprofundada, supostamente mais coerente, dos princípios estabelecidos pelos grandes iluministas franceses do século XVIII [...]" (ENGELS, 2015, p. 45), mas fundada na prioridade basilar atribuída à produção material da vida e à percepção, nesse campo, dos antagonismos existentes. Da tradição materialista até Feuerbach, Marx incorpora a noção de uma realidade que existe objetivamente (e não como produto da consciência). Porém, como esse materialismo ingênuo (metafísico) desconsiderava o polo subjetivo (a atividade humana necessária à elaboração do conceito a partir da atividade sensorial), este será apropriada por Marx do idealismo, caracteristicamente em Hegel, muito embora, neste último, a atividade humana se encontrasse de forma abstrata, mistificada, isto é, "[...] o idealismo não conhece a atividade real, sensível como tal" (MARX, 2007, p. 537).

O socialismo utópico, por sua vez, concorreria com “[...] embriões de ideias e os pensamentos geniais que irrompem por todo lado do invólucro fantasioso [...]” (ENGELS, 2015, p. 291), teorias imaturas, porém as únicas possíveis para um estágio ainda incipiente de desenvolvimento da sociedade capitalista. A economia clássica inglesa constituiria outra importante fonte de construções teóricas (como a teoria do valor-trabalho) a serem continuadas e superadas na elaboração da economia política que ultrapassasse o ponto de vista unilateral burguês.

A síntese constituída a partir dessas diversas fontes - filosóficas, políticas e econômicas -, entretanto, muito além de uma mera justaposição, é de uma tal riqueza que Gramsci (1995) aponta a impropriedade de se compreenderem tais influências "[...] no sentido de que cada

Argum., Vitória, v. 10, n. 2, p. 70-83, maio/ago. 2018. 
um desses movimentos contribuiu para elaborar, respectivamente a filosofia, a economia e a política da filosofia da práxis [...]” (GRAMSCI, 1995, p. 110), afirmando, antes, tratar-se de uma síntese que "[...] em qualquer momento que se a examine, momento teórico, econômico, político, se reencontra como 'momento' preparatório cada um dos três movimentos" (GRAMSCI, 1995, p. 110).

As elaborações de Marx e Engels, sempre articuladas às lutas coletivas contra a opressão, estabeleceram, com essa síntese, nada menos do que uma nova concepção de mundo que incorporava a contradição como elemento da materialidade histórica (GRAMSCI, 1995). Fruto do laborioso esforço de interpretação/transformação no campo específico (e central) da produção material humana, o materialismo histórico e dialético revelaria, de forma geral, a tendência à contradição crescente entre o desenvolvimento das forças produtivas e as relações de produção em determinado modo de produção da vida material, com o que, tendencialmente, “[...] abre-se, então, uma época de revolução social” (MARX, 2008, p. 47).

A partir da teoria da mais-valia, os estudos marxianos denunciaram a opressão na sociedade capitalista na forma de exploração da parte não paga da produção de valor realizada pelo trabalhador assalariado. Sustentaram também, através da análise da dinâmica do capital, a incompatibilidade do atual modo de produção com a real (não só formal) emancipação humana, dada a recorrente produção de crises de acumulação, a tendência decrescente da taxa de lucros, a crescente concentração monopolista, dentre outros elementos. Defenderam, assim, a superação revolucionária do capitalismo como uma necessidade incontornável. O materialismo histórico desenvolve, igualmente, as bases teóricas para a compreensão das possibilidades, das formas organizativas, enfim, das linhas mestras de construção do projeto político de superação do capital. Articula inseparavelmente, portanto, o método crítico-dialético, a teoria do valor-trabalho e a perspectiva da revolução. "Sem a presença simultânea destes três componentes, a sua construção teórica desaba” (NETTO 1989, p. 95).

Tal conjunto de elementos analíticos, portadores de incisiva denúncia, e de um projeto que tem em vista nada menos que extirpar da sociedade humana a produção social orientada à obtenção de mais-valia, seguramente seriam alvo de extrema hostilidade das classes hegemônicas, que se manifesta tanto na perseguição aberta aos seus defensores ${ }^{4}$ como no campo da "batalha das ideias", promovendo a descaracterização e desqualificação de seu conteúdo. Paradoxalmente, entretanto, muitas distorções acabaram se dando no interior do próprio campo marxista, no qual, conforme Netto (2011),

[...] as deformações tiveram por base as influências positivistas, dominantes nas elaborações dos principais pensadores (Plekhanov, Kautsky) da Segunda Internacional [...]. Essas influências não foram superadas - antes se viram agravadas, inclusive com incidências neopositivistas - no desenvolvimento ideológico ulterior da Terceira Internacional [...], culminando na ideologia stalinista (NETTO, 2011, p. 12).

\footnotetext{
${ }^{4}$ Netto (2011) observa que, nas sociedades ditas democráticas, “[...] ninguém teve seus direitos civis ou políticos limitados por ser durkheimiano ou weberiano - mas milhares de homens e mulheres, cientistas sociais ou não, foram perseguidos, presos, torturados, desterrados e até mesmo assassinados por serem marxistas" (NETTO, 2011, p. 10).
}

Argum., Vitória, v. 10, n. 2, p. 70-83, maio/ago. 2018. 
Tais deformações se expressavam em reducionismos que acabavam por separar rigidamente teoria e prática, estabeleciam um marxismo cientificista e incorriam em um pronunciado esquematismo ao tratar de categorias como "materialismo dialético", "materialismo histórico", "leis da dialética" etc., esvaziando-as da sua riqueza e favorecendo interpretações não-dialéticas, como é o caso do "determinismo econômico". A "vulgata stalinista" contribuiu sobremodo com esse esvaziamento, que exigiu o esforço de resgate do pensamento marxiano por parte de diversos pensadores, como Gramsci e Lukács, dentre outros. Vázquez (2007) igualmente aponta a "[...] necessidade de superar o dogmatismo e a esclerose que durante longos anos havia menoscabado o fio crítico e revolucionário do marxismo" (VÁZQUEZ, 2007, p. 19).

Além das referidas distorções, a possibilidade de assimilação do legado marxiano pela esquerda, com toda sua potência transformadora, é comprometida, ainda, pelo problema da fortuna editorial de Marx, com a existência de obstáculos de diversas ordens para a difusão ampliada da sua obra em bases confiáveis. Bastaria, para demonstrá-lo, a afirmação de que "[...] o marxismo é originalmente construído sem o aporte de substantivas reflexões de Marx" (NETTO, 2015, p. 5)5. Assim, diversas compreensões do marxismo, ao longo do século $\mathrm{XX}$, incorreram em significativas divergências com relação, por exemplo, ao efetivo valor das obras do "jovem Marx”, ou à importância de categorias fundamentais como alienação.

Alguns aspectos fundamentais do marxismo, como o método de produção do conhecimento, ainda são atravessados por interpretações redutoras, uma vez que pensar segundo a lógica dialética exige a ruptura com uma tradição secularmente arraigada da lógica formal, típica da tradição positivista, que exclui a contradição.

\section{O MÉTODO MARXIANO: INTERPRETAÇÃO E TRANSFORMAÇÃO DA REALIDADE}

O desenvolvimento do método marxiano não foi determinado por um interesse teórico em si, mas deu-se de forma orgânica a um projeto de compreensão e transformação revolucionária da sociedade; foi elaborado como decorrência e em função desse projeto. A exigência se impôs diante do desafio de expressar em categorias teóricas as contradições já identificadas (entre classes, propriedade, privação etc.). Tal exigência promoverá a reabilitação da dialética, que, até então, vinha sendo rechaçada por Marx e Engels. Concorrem aí, inclusive, elementos fortuitos, conforme carta de Marx a Engels, de janeiro de 1858:

\footnotetext{
No método de elaboração, fui muito bem servido, porque acidentalmente (Freiligrath havia encontrado alguns volumes de Hegel que haviam pertencido a Bakunin e os enviara para mim como presente), eu voltei a me ocupar da Lógica de Hegel. Quando houver oportunidade para tal trabalho, terei grande prazer de tornar acessível ao público em duas ou três folhas impressas, o elemento racional do método descoberto e, ao mesmo tempo, mistificado por Hegel (LEFEBVRE, 1999, p. 56-57, tradução dos autores).
}

\footnotetext{
$5 \mathrm{O}$ autor destaca que "[...] figuras essenciais na constituição e desenvolvimento da tradição marxista não conheceram textos fundamentais de Marx - Kautsky, Plekhanov, R. Luxemburgo, Lênin e Gramsci, por exemplo, produziram suas obras sem ter acesso aos Cadernos de Paris, aos Manuscritos EconômicoFilosóficos de 1844, a A ideologia alemã e aos Grundrisse" (NETTO, 2015, p. 5, grifos do autor).
}

Argum., Vitória, v. 10, n. 2, p. 70-83, maio/ago. 2018. 
Entretanto, tal reencontro com Hegel só fez sentido por convergir com produções já realizadas por Marx. Cabe destacar aqui o papel decisivo das Teses sobre Feuerbach, no sentido de que estas iriam situar "[...] a atividade prática humana no centro de sua concepção [...]" (VÁZQUEZ, 2007, p. 140), consolidando, portanto, os traços fundamentais de uma filosofia da práxis, com a nítida presença de elementos dialéticos que antecipam o método que virá. Desenvolve-se, já aqui, uma concepção de objetividade fundada na práxis, em uma síntese entre o materialismo existente até então e o idealismo.

O método marxiano do conhecimento pressupõe necessariamente duas vias: parte do conjunto de apreensões imediatas de certo objeto e, analiticamente, segue por meio de "[...] abstrações cada vez mais tênues, até alcançar as determinações mais simples” (MARX, 2008, p. 258). Porém, “[...] chegado a esse ponto, teria que fazer a viagem de modo inverso [...]" (MARX, 2008, p. 258) em direção ao objeto da representação inicial, mas agora "[...] como uma rica totalidade de determinações e relações diversas” (MARX, 20o8, p. 258). Em suma, das representações abstratas, reproduz-se o concreto no pensamento.

O concreto é concreto porque é a síntese de muitas determinações, isto é, unidade do diverso. Por isso, o concreto aparece no pensamento como o processo da síntese, como resultado, não como ponto de partida, embora seja o verdadeiro ponto de partida e, portanto, o ponto de partida da intuição e da representação (MARX, 2008, p. 258-259).

Marx (2008) recusa o reducionismo e, ao mesmo tempo, realiza uma síntese a partir do materialismo metafísico e do idealismo. O pensador ocupa-se em refutar, em especial, esta última posição ${ }^{6}$, que admite somente o movimento do abstrato ao concreto. Contudo, incorpora-a no seu devido lugar como parte do método de elaboração do conhecimento ou como "[...] a maneira de proceder do pensamento para se apropriar do concreto, para reproduzi-lo mentalmente como coisa concreta" (MARX, 2008, p. 259). Para a consciência filosófica (isto é, para o idealismo),

[...] o movimento das categorias aparece como o verdadeiro ato de produção - que apenas recebe um impulso do exterior - cujo resultado é o mundo, e isso é exato porque (aqui temos de novo uma tautologia) a totalidade concreta, como totalidade de pensamento, como uma concreção de pensamento, é, na verdade, um produto do pensar, do conceber [...] O todo, tal como aparece no cérebro, como um todo mental, é um produto do cérebro pensante, que se apropria do mundo da única maneira em que o pode fazer (MARX, 2008, p. 259).

Em sua reiterada polêmica com o idealismo, Marx (2008) afirma que "[...] o objeto concreto permanece em pé antes e depois, em sua independência e fora do cérebro ao mesmo tempo" (MARX, 2008, p. 260). Tal afirmação pode sugerir uma concepção de determinação unilateral da realidade em relação à consciência, isto é, que a consciência em nada determina o real. Mas tal unilateralidade é apenas aparente, caso se considere que se trata, aqui, de uma afirmação polêmica contra o idealismo, e que, na abordagem dialética, cada

\footnotetext{
${ }^{6}$ Registre-se que essa elaboração marxiana ocorre em um período de forte hegemonia do idealismo nos círculos filosóficos, ou, nas palavras de Bloch (2005, p. 252), "[...] numa época em que em toda esquina acadêmica repercutia o espírito, o conceito e mais uma vez o conceito" (BLOCH, 2005, p. 252).
}

Argum., Vitória, v. 10, n. 2, p. 70-83, maio/ago. 2018. 
negação leva a nova síntese. Em diversas situações, Marx demonstra que um elemento determinado também atua, reciprocamente, como determinante?7.

Na célebre passagem em que Marx trata do caráter determinado da consciência, o pensador afirma que "[...] não é a consciência que determina a vida, mas a vida que determina a consciência” (MARX, 2007, p. 94). Ao empregar o termo vida, Marx coloca o acento na determinação a partir da atividade do ser humano que transforma a realidade e se autotransforma, que produz continuamente, na práxis, sua própria essência. Não se trata, aqui, de forma alguma, de uma determinação a partir de uma realidade absolutamente separada da atividade objetiva humana e projetada unilateralmente na consciência.

A Figura 1, em que Dussel (2012) apresenta um esquema representativo das diversas etapas da produção do conhecimento científico, revela, não obstante a inegável prioridade ontológica da realidade em relação à consciência, a existência de reciprocidade de determinações. O Mundo conceptualizado, que já inicia na representação caótica (nível fenomênico) do todo, não só recebe influência do Mundo real, mas, após o processo de análise/síntese, retorna em interferência ao Mundo real, já que então se tem a Realidade conhecida. Conforme indica esse esquema, o processo de conhecimento da realidade é cíclico e interminável; entretanto, a cada retorno, tem-se uma mudança do caráter do Real concreto, especialmente, cabe acrescentar, em se tratando do conhecimento da realidade social.

\section{FIGURA 1}

CLARIFICAÇÃO APROXIMADA DOS DIVERSOS MOMENTOS METODOLÓGICOS

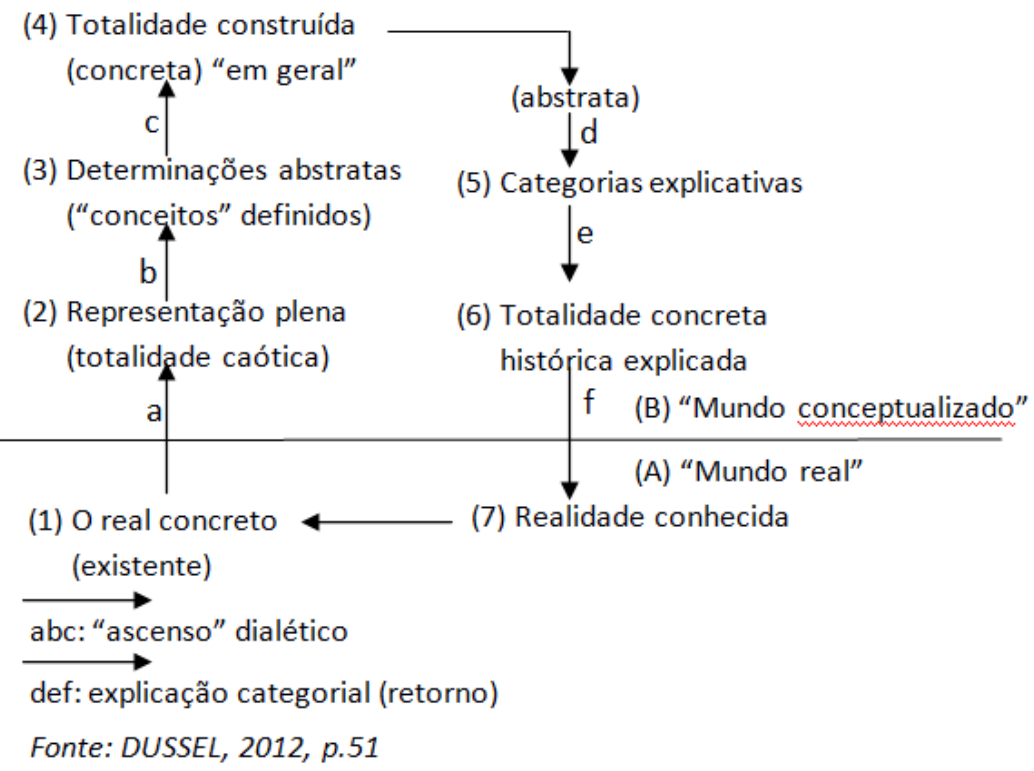

\footnotetext{
7 Veja um exemplo na discussão da determinação da produção em relação à distribuição, à troca e ao consumo: "Uma [forma] determinada da produção determina, pois, [formas] determinadas do consumo, da distribuição, da troca, assim como relações recíprocas determinadas desses diferentes fatores. A produção, sem dúvida, em sua forma unilateral, é também determinada por outros momentos; por exemplo, quando o mercado, isto é, a esfera das trocas, se estende, a produção ganha em extensão e divide-se mais profundamente. Se a distribuição sofre uma modificação, também varia a produção; por exemplo, com a concentração do capital, com uma distribuição diferente da população na cidade e no campo etc. Enfim, a necessidade de consumo determina a produção. Uma ação recíproca ocorre entre os diferentes momentos. Esse é o caso para cada todo orgânico" (MARX, 2008, p. 257, grifos do autor).
}

Argum., Vitória, v. 10, n. 2, p. 70-83, maio/ago. 2018. 
Netto (2011), após afirmar que o objeto de pesquisa tem "[...] uma existência objetiva, que independe da consciência do pesquisador [...]” (NETTO, 2011, p. 22), enfatiza, em contraponto, que "[...] a relação sujeito/objeto no processo do conhecimento teórico não é uma relação de externalidade, tal como se dá, por exemplo, na citologia ou na física; antes, é uma relação em que o sujeito está implicado no objeto" (NETTO, 2011, p. 23).

Ianni (2011), da mesma forma, discute essa reciprocidade de determinações, enfatizando, inicialmente, o papel central da construção das categorias no método dialético. $\mathrm{O}$ autor resgata uma reflexão de Hegel, retomada por Marx, segundo a qual, "[...] o fato que é destituído de conceito, que não está categorizado, é um fato que está perdido” (IANNI, 2011, p. 397). Nesse sentido, "Explicar a realidade [...] é ajudar essa realidade a se constituir. Portanto, o pensamento entra na constituição do real” (IANNI, 2011, p. 397). Para o autor, um exemplo de como uma categoria reconstrói um elemento da realidade, que (potencial e efetivamente) passa na prática humana a ser encarado de outra forma, é o

\begin{abstract}
Trabalho geral abstrato, que está no primeiro capítulo do 'O Capital' e que é fundamental para a compreensão de vários outros capítulos. Não é dado empiricamente [...]. Porque a mercadoria não é um trabalho cristalizado, é matéria, é couro, é ferro, é tinta, é tecido, não é trabalho. [...] na verdade é o resultado de uma reflexão obstinada sobre a realidade que desvenda o segredo da mercadoria, que é ser trabalho cristalizado (IANNI, 2011, p. 398).
\end{abstract}

Contribui também com a discussão da dialética compreender/transformar, o destaque feito por Netto (2011) sobre o duplo caráter das categorias, como objetivas, reais, pertencentes à ordem do ser (categorias ontológicas) e à ordem da abstração intelectiva, da reprodução teórica (categorias reflexivas). Tal destaque converge com a posição de Ianni (2011) a respeito do duplo caráter das categorias, que acentua a necessidade da crítica: desvendar o real é aproximar continuamente as categorias no plano do pensamento à sua contrapartida como constituinte do real, mediante uma luta com outras interpretações ${ }^{8}$.

Vale, ainda, agregar aqui a reflexão gramsciana sobre a relação possibilidade/realidade. O conhecimento da realidade (possibilidade realizada) se revela como força a converter possibilidades (realidades potenciais) no móvel da liberdade, do saber e do querer transformar.

\begin{abstract}
A possibilidade não é a realidade, mas é, também ela, uma realidade: que o homem possa ou não possa fazer determinada coisa, isto tem importância na valorização daquilo que realmente se faz. Possibilidade quer dizer 'liberdade'. [...] Mas a existência das condições objetivas - ou possibilidade, ou liberdade - ainda não é suficiente: é necessário 'conhecê-las' e saber utilizá-las. Querer utilizá-las (GRAMSCI, 1995, p. 47).
\end{abstract}

\footnotetext{
8 Marx, quando, por exemplo, estuda as determinações da economia capitalista se defronta tanto com a realidade, quanto com as explicações já realizadas (Smith, Ricardo etc.) dessa realidade. Tal esforço inseparável, segundo Ianni (2011), decorre do fato de que a realidade está sempre impregnada de interpretações.
}

Argum., Vitória, v. 10, n. 2, p. 70-83, maio/ago. 2018. 


\section{A SUPERAÇÃO DO CAPITALISMO E A NECESSIDADE DE MEDIAÇÕES TEÓRICO/PRÁTICAS}

Lênin, com uma profunda compreensão do legado marxiano, defende, de acordo com a lógica dialética, que não separa rigidamente forma de conteúdo, o princípio da "análise concreta da realidade concreta". Tal princípio ancora-se na convicção de que o interesse de Marx "[...] não incidia sobre um abstrato 'como conhecer', mas sobre 'como conhecer um objeto real e determinado” (NETTO, 2011, p. 27). Efetivamente, o método marxiano ganha tal centralidade que Lukács estabelece nele o critério da ortodoxia marxista, vinculada não à adesão incondicional aos resultados a que Marx chegou, mas referida,

[...] antes e exclusivamente, ao método. Ela implica a convicção científica de que, com o marxismo dialético, foi encontrado o método de investigação correto, que esse método só pode ser desenvolvido, aperfeiçoado e aprofundado no sentido dos seus fundadores, mas que todas as tentativas de superá-lo ou 'aperfeiçoá-lo' conduziram somente à banalização, a fazer dele um ecletismo - e tinham necessariamente de conduzir a isso (LUKÁCS, 2003 p. 64, grifos do autor).

Com efeito, uma incisiva apreensão do legado marxiano, e do adequado lugar do método dialético, permitiu que determinados estudiosos tenham-se constituído continuadores dessa tradição teórica. Esses estudiosos, precisamente por essa aguda apreensão do método, voltando-se, porém, a uma realidade com um grau de desenvolvimento capitalista ainda não presenciado no século XIX, chegam a rever ou dar o devido desenvolvimento a certos resultados a que Marx chegou9. Cabe destacar que tais elaborações sempre estiveram sujeitas a fortes controvérsias no campo do marxismo, em especial nos casos em que elas parecem se afastar dos resultados encontrados por Marx, especificamente sobre a análise da sociedade capitalista, papel do Estado, e as estratégias para o processo revolucionário.

Agregando-se a essas controvérsias, o fenômeno já citado de degradação do marxismo, pela via das formulações dogmáticas, do esquematismo etc., fica claro o desafio colocado para que o riquíssimo legado marxiano se converta em força efetiva da transformação revolucionária. Como exemplos de notáveis intervenções na análise da realidade, com importantes consequências no campo da ação revolucionária, cabe aqui destacar dois casos (com Lênin e Gramsci), que podem ser compreendidos como mediações teórico/práticas dos fundamentos do método marxiano a situações históricas concretas.

A análise feita por Lênin das condições específicas da sociedade russa no final do século XIX, e suas conclusões sobre o correto encaminhamento da luta revolucionária naquele país, colocam-no no centro de uma acirrada polêmica com aqueles que defendiam a possibilidade de chegada ao socialismo sem passar pelo desenvolvimento capitalista. Lênin coloca em questão o nível do desenvolvimento do capitalismo russo, concluindo que seria

\footnotetext{
9 Cumpre, aqui, assinalar que não há completa unidade entre os autores citados, seja quanto a suas interpretações do legado marxiano, seja quanto à contribuição específica de cada um. Por outro lado, no que diz respeito à compreensão da centralidade do método marxiano, há forte convergência entre eles quanto à apreensão da dinâmica da sociedade capitalista em cada fase histórica e, em forte vinculação a este ponto, quanto à reelaboração da teoria e da prática revolucionária, de acordo com os fundamentos do materialismo histórico-dialético.
}

Argum., Vitória, v. 10, n. 2, p. 70-83, maio/ago. 2018. 
indispensável a revolução burguesa (com as transformações democráticas, sociais e econômicas correlatas), e sem a qual,

[...] mesmo o triunfo completo da insurreição camponesa, mesmo uma nova divisão de todas as terras conforme os interesses e segundo os desejos dos camponeses [...], longe de suprimir o capitalismo, revigoraria, pelo contrário, seu desenvolvimento e precipitaria a diferenciação de classes no seio dos camponeses (LÊNIN, 1978, p. 70).

Afirmava, portanto, que a revolução burguesa era, contraditoriamente, de imenso interesse para o proletariado; e, mais que isso, que este deveria "[...] participar dela da maneira mais enérgica, travar a luta mais resoluta pela democracia proletária consequente, pelo remate da revolução" (LÊNIN, 1978, p. 70).

Gramsci, por sua vez, traz uma contribuição primordial para a compreensão das possibilidades da luta revolucionária no século XX. Trata-se de um conjunto articulado de categorias que expressam o caráter próprio das sociedades capitalistas que ele irá denominar de "ocidentais" : hegemonia, sociedade civil, guerra de movimento, guerra de posição etc. Trata-se de uma teoria ampliada do Estado que destaca, nas sociedades ocidentais, uma relação equilibrada entre sociedade civil e sociedade política.

[Nos] Estados mais avançados, [...] a 'sociedade civil' tornou-se uma estrutura muito complexa e resistente às 'irrupções' catastróficas do elemento econômico imediato (crises, depressões, etc.): as superestruturas da sociedade civil são como o sistema das trincheiras na guerra moderna (GRAMSCI, 2007, p. 73).

Gramsci sustenta, em polêmica com outros importantes marxistas, como Trotsky e Rosa Luxemburgo, que uma guerra de movimento, visando ao assalto ao poder poderia se constituir em mero voluntarismo, ação temerária fadada ao fracasso.

Na guerra de posição, a conquista gradativa de posições (conquista de direção políticoideológica e do consenso dos setores majoritários da população) ocupa o lugar central. Em suma, na estratégia gramsciana de transição ao socialismo, para a obtenção de resultados mais estáveis e duradouros, torna-se imprescindível a etapa de transformação da classe dominada em classe dirigente, antes da tomada do poder (GRAMSCI, 2007; COUTINHO, 1999).

\section{CONSIDERAÇÕES FINAIS: OS DESAFIOS PARA A ESQUERDA E O LEGADO MARXIANO}

Marx e Engels, em A Ideologia Alemã, apresentam a célebre assertiva de que a consciência humana é produto do ser social. Dessa forma, a própria consciência desses pensadores foi determinada por seu tempo histórico, isto é, o século XIX, muito embora sua elaboração teórica contenha elementos cuja validade extrapola aquele período. Por esse motivo, a tarefa de transformação do mundo pela esquerda deverá, incorporando aqueles elementos que

10 Ocidentalização, ressalte-se, não é um fato puramente geográfico, mas primordialmente histórico: sociedades se ocidentalizam na medida em que ocorre a "ampliação" do Estado, isto é, evolui o equilíbrio entre sociedade política e sociedade civil (COUTINHO, 1999).

Argum., Vitória, v. 10, n. 2, p. 70-83, maio/ago. 2018. 
mantém sua validade, avançar em relação ao pensamento marxiano, notadamente naqueles aspectos limitados pelo que estava posto no seu tempo de vida.

Como parte do atual desafio histórico, assiste-se, na atualidade, a uma clara fragmentação das lutas sociais e das manifestações de resistência dentro do denominado campo da esquerda e/ou do campo progressista. Parte dessa fragmentação deve-se à expansão do irracionalismo pós-moderno que, dentre outras discussões, questiona o sujeito revolucionário anunciado pela teoria marxiana - o proletariado - e para isso, no quadro de uma recusa geral a qualquer abordagem totalizante, dirige pesadas críticas à centralidade das categorias trabalho e luta de classes, essenciais para o marxismo.

Decerto as discussões da pós-modernidade contribuíram para colocar devidamente, no campo das lutas políticas, as dimensões das históricas opressões de gênero, raça, etnia, geração e sexualidade. É notável o avanço político e os relativos ganhos dos movimentos de mulheres, negros, LGBT e indígenas, que têm pautado a questão das opressões, dos preconceitos e das expressões de ódio, presentes no cotidiano. É importante considerar, no tempo presente, que a esquerda deve incluir decididamente as lutas organizadas em torno do campo das opressões ${ }^{11}$, porém no interior de um projeto anticapitalista, referenciado na centralidade das lutas contra a exploração de classe. É fundamental que a esquerda não abra mão de se fundamentar na racionalidade dialética para buscar a essência das contradições do capital, que está na raiz de todas as formas de dominação na sociedade contemporânea.

Na luta anticapitalista, a centralidade da relação capital/trabalho é imperiosa porque as "[...] contradições internas do capital que foram responsáveis pelas crises recentes [...] dão a entender que não há saída sem a destruição da vida e da subsistência de milhões de pessoas no mundo todo" (HARVEY, 2016, p. 21). Essa destruição continuará a afetar os seres humanos que, no geral, vivem do seu trabalho (homens, mulheres, negros, indígenas, gays, lésbicas), ou seja, pessoas do gênero humano, em especial os pobres ao redor do mundo.

Retomando-se a formulação de Lênin acerca da necessidade da "análise concreta da realidade concreta", tem-se que a exploração de classe e as opressões (que incluem a questão das identidades) não são dissociadas, como muitas vezes aparentam estar, no interior das lutas sociais. Ao contrário, estão articuladas na vida concreta, dada a existência e a continuidade das contradições fundadas na desigualdade econômica e social, que tem por base a divisão do trabalho e ganha expressões inéditas na ordem burguesa pela grave expansão da barbárie em todos os níveis da vida social ${ }^{12}$.

Essa tarefa inclui a necessidade da radical apreensão de determinações, como a dinâmica global de produção da mais valia, a financeirização da economia, a crescente captura do Estado pelas frações de classe dominante (vinculada à hegemonia da ideologia neoliberal na sua vertente ultraconservadora), o poder dos meios de comunicação de massa, que incidem

\footnotetext{
${ }^{11}$ Não é possível se pensar a construção de uma sociedade emancipada com a existência de qualquer tipo de dominação.

12 Não cabe, neste ensaio, discutir extensamente este tema, mas vale citar a tragédia diária por que passam jovens do sexo masculino, pobres, negros e moradores da periferia, que são assassinados por estarem envolvidos no tráfico de drogas. Salta aos olhos a impossibilidade de se separar, na interpretação e na luta, a dimensão de classe da de raça, gênero e geração, presentes nessa brutal realidade.
}

Argum., Vitória, v. 10, n. 2, p. 70-83, maio/ago. 2018. 
na destruição da natureza, as diversas formas de alienação, guerra, migrações, tráfico de drogas etc. Como afirma Coutinho,

\begin{abstract}
Uma caracterização sistemática de nossa época - ou seja, a época da globalização ou mundialização do capital, caracterizada pelo predomínio de políticas neoliberais - é uma tarefa ainda não concluída por parte dos marxistas. Para levá-la a cabo é necessária uma ampla análise de natureza teórica e empírica, que traga até o nosso tempo - atualizando-as e revisando-as quando preciso - as categorias da crítica da economia política iniciada por Marx e continuada por muitos de seus principais seguidores [...] (COUTINHO, 2012, p. 117).
\end{abstract}

A tarefa revolucionária da esquerda, portanto, é apreender e articular - pela via da racionalidade dialética - o que aparentemente é desorganizado ou fragmentado, ou seja, é apreender as mediações contraditórias existentes na realidade e que se articulam à dominação de classe. É fundamental a referência à totalidade histórica, enfrentando-se as mistificações teóricas que põem a centralidade da produção do conhecimento, ora no sujeito, ora no objeto, em claro empobrecimento da razão, empregando-se a expressão de Coutinho (2010).

Por outro lado atualizam-se as questões apontadas pela tradição marxista: quais são os sujeitos revolucionários na contemporaneidade? Quais as mediações concretas na construção do socialismo? De que forma a práxis social (especialmente dos trabalhadores empobrecidos) poderá ser orientada pela produção do conhecimento, para além do senso comum/prático mental ou religioso? Qual o papel das lutas sociais no interior da ordem burguesa, articuladas ao processo de democratização radical e às demandas de acesso às políticas públicas? No âmbito da guerra de posição, isto é, na disputa pela crescente conquista de espaços de hegemonia no âmbito da sociedade civil (GRAMSCI, 2007), quais as mediações possíveis através de instrumentos de luta, como sindicatos, partidos políticos, movimentos sociais urbanos e rurais, coletivos urbanos, organizações indígenas e de comunidades tradicionais, associações científicas, educação escolar?

Frente à atual tendência à fragmentação no campo das lutas sociais, não se pode perder de vista a perspectiva da totalidade da vida social, não como elemento que, por si só, assegure o avanço emancipatório, mas como componente indispensável do esforço de compreensão/transformação do mundo, sempre sujeito a múltiplas determinações históricas. Tal perspectiva se funda, necessariamente, na produção material e imaterial voltada à satisfação das necessidades do gênero humano, que se traduz na possibilidade de incorporação universalizada das inúmeras objetivações construídas historicamente pelo ser social.

É importante que a esquerda possa, ela mesma, debruçar-se em esforços profundos de formação teórica - pela necessária incorporação da ortodoxia do método dialético -, sem os quais não é possível a interpretação das determinações históricas das contradições do tempo presente, bem como a construção das mediações (igualmente históricas) para a construção do projeto revolucionário que se volte à sociedade emancipada.

\title{
REFERÊNCIAS
}

BLOCH, Ernest. O Princípio esperança. Rio de Janeiro: Contraponto, 2005.

Argum., Vitória, v. 10, n. 2, p. 70-83, maio/ago. 2018. 
COUTINHO, Carlos Nelson. A época neoliberal: revolução passiva ou contra-reforma? Revista Novos Rumos, Marília, v. 49, n. 1, p. 117-126, jan./jun. 2012.

COUTINHO, Carlos Nelson. O estruturalismo e a miséria da razão. Posfácio de José Paulo Netto. 2. ed. São Paulo: Expressão Popular, 2010.

COUTINHO, Carlos Nelson. Gramsci: um estudo sobre seu pensamento político. Rio de Janeiro: Civilização brasileira, 1999.

DUSSEL, Enrique. A produção teórica de Marx: um comentário aos Grundisse. Tradução José Paulo Netto. São Paulo: Expressão Popular, 2012.

ENGELS, Friedrich. Anti-Dühring: a revolução da ciência segundo o senhor Eugen Dühring. São Paulo: Boitempo, 2015.

GRAMSCI, Antonio. Cadernos do Cárcere. v. 3. 3. ed. Rio de Janeiro: Civilização Brasileira, 2007.

GRAMSCI, Antonio. Concepção dialética da história. Rio de Janeiro: Civilização Brasileira, 1995.

HARVEY, David. 17 contradições e o fim do capitalismo. São Paulo: Boitempo; Loyola, 2016.

IANNI, Octávio. A construção da categoria. Revista HISTEDBR On-line, Campinas, número especial, p. 397-416, abr. 2011. Disponível em:

<http://www.abepss.org.br/arquivos/anexos/ianni-201804131230457141340.pdf>. Acesso em: 6 abr. 2018.

LEFEBVRE, Henri. El materialismo dialéctico. Psikolibro, 1999. Disponível em:

$<$ https://www.infoamerica.org/documentos_pdf/el_materialismo_dialectico.pdf $>$. Acesso em: 14 abr. 2018.

LÊNIN, Vladimir. A revolução burguesa e os dois tipos de democracia. In: FERNANDES, F. (Org.). Lênin: política. São Paulo: Ática, [1905] 1978. p. 70-82. (Coleção Grandes Cientistas Sociais).

LUKÁCS, György. História e consciência de classe: estudos sobre a dialética marxista. São Paulo: Martins Fontes, 2003.

MARX, Karl. Contribuição à crítica da economia política. 2. ed. São Paulo: Expressão Popular, 2008.

MARX, Karl. Marx sobre Feuerbach (1845). [Com alterações de Engels, 1888]. In: A ideologia alemã. São Paulo: Expressão Popular, 2007. 
NETTO, José Paulo. Breve nota à interlocução entre pensadores da educação e Marx. In: REUNIÃO NACIONAL DA ANPED, 37, 2015, Florianópolis. Anais... Florianópolis: UFSC, 2015. p. 1-31.

NETTO, José Paulo. Introdução ao estudo do método em Marx. São Paulo: Expressão Popular, 2011.

NETTO, José Paulo. O Serviço Social e a tradição marxista. Revista Serviço Social \& Sociedade, São Paulo: Cortez, v. 10, n. 30, p. 89-102, 1989.

VÁZQUEZ, Adolfo S. Filosofia da práxis. São Paulo: Expressão Popular, 2007.

Benedito de Jesus Pinheiro FERREIRA trabalhou na concepção e delineamento do artigo; elaboração conceitual das seções sobre a tradição marxista e o método marxiano; redação do artigo e sua revisão crítica; ajustes e aprovação da versão final a ser publicada.

Doutor em Engenharia de Sistemas e Computação pela UFRJ. Professor Titular do Programa de Pós-graduação em Educação e da Faculdade de Computação da UFPA.

Joana Valente SANTANA trabalhou na concepção e delineamento do artigo; elaboração teórica conceitual da seção que trata das mediações das categorias marxianas para superação do capitalismo e os desafios para a esquerda com base no legado marxiano; redação do artigo e sua revisão crítica; ajustes e aprovação da versão final a ser publicada.

Doutora em Serviço Social pela UFRJ. Professora Associada II do Programa de Pós-graduação em Serviço Social e da Faculdade de Serviço Social da UFPA. Bolsa Produtividade em Pesquisa (PQ2)/CNPq. 